\title{
A model to predict changes in resilient modulus resulting from wetting and drying
}

\section{Modelo para predecir los cambios en el módulo de resiliencia debidos a humedecimiento y secado}

\section{Natalia Perez-Garcia}

Mexican Transportation Institute, Mexico

nperez@imt.mx

\section{Delwyn Fredlund}

Golder Associates, Canada

unsaturatedsoil@yahoo.com
Paul Garnica-Anguas

Mexican Transportation Institute, Mexico

pgarnica@imt.mx

\section{Noe Mestas-Martinez}

Oaxaca Institute of Technology, Mexico

noe.mestas@gmail.com

Fecha de recepción: 20 de noviembre de 2015 / Fecha de aprobación: 12 de enero de 2016

\section{RESUMEN}

El módulo de resiliencia es uno de los parámetros más importantes para el diseño de pavimentos, sin embargo, éste no se mantiene constante después de la construcción de la obra sino que presenta cambios estacionales debidos a humedecimiento o secado de los materiales. Por tanto, los cambios en este parámetro deben ser contemplados en el diseño. La literatura sobre este tema es amplia para países extranjeros, sin embargo, para México es escasa. En este artículo los autores muestran resultados de una investigación cuyo objetivo fue obtener un modelo para predecir los cambios en el módulo de resiliencia debidos a humedecimiento o secado de suelos como arcillas, limo y arena. La metodología fue preparar varios especímenes en el óptimo de compactación (con respecto a la prueba Proctor estándar); posteriormente varios especímenes se humedecieron por capilaridad y otros se secaron al aire, con el propósito de simular condiciones posteriores a la construcción. Después del acondicionamiento de los especímenes, éstos fueron ensayados en la prueba de módulo de resiliencia de acuerdo con el protocolo NCHRP 1-28A. Los resultados indicaron que el módulo de resiliencia puede predecirse usando un modelo en función del esfuerzo desviador y del confinamiento $\left(\sigma_{\mathrm{d}} / \sigma_{3}\right)$ y la variación del contenido de agua con respecto a la humedad óptima. Al graficar los datos de módulo de resiliencia obtenidos en laboratorio contra los predichos con el modelo se obtuvo un valor de coeficiente de correlación $\left(\mathrm{R}^{2}\right)$ de $84.1 \%$, lo cual indica que el modelo es adecuado para predecir este parámetro.

PALABRAS CLAVE: diseño de pavimento, pruebas triaxiales de carga repetida, trayectorias de humedecimiento y secado, modelo de módulo de resiliencia.

\section{ABSTRACT}

The resilient modulus of a soil is an important parameter needed for pavement design. However, this parameter experiences post-compaction seasonal changes during the service life of the pavement as a result of wetting or drying of the soil during dry or rainy periods. Variations in the resilient modulus should be introduced into pavement design methodologies. Research literature shows resilient modulus results from other countries; however, the information is scarce for Mexican soils. In this paper, the authors show results of a research carried out in the laboratory to evaluate a model for the prediction of the effect of wetting and drying on the resilient modulus of soils classified as clays, silt, and sand. Several samples were prepared at optimum conditions using the Proctor standard test. Some specimens were then dried by allowing a loss of water through evaporation while others were allowed to gain water through capillarity (assumed to simulate post-compaction conditions). After the samples were conditioned to new water contents, resilient modulus tests were performed following the NCHRP 1-28A protocol. The results show that the resilient modulus can be predicted using a model which is a function of the deviator stress and confining pressure (i.e., $\left.\left(\sigma_{d} / \sigma_{3}\right)\right)$ and the variation of water content from optimum water content conditions (i.e., the condition after field compaction). The $R^{2}$ between predicted and measured results was $84.1 \%$.

KEYWORDS: Pavement design, repeated loading triaxial tests, drying and wetting paths, resilient modulus model. 


\section{INTRODUCTION}

Resilient modulus is a parameter that has caught the attention of pavement design researchers around the world. Studies related to resilient modulus can be summarized as follows: i.) effect of testing protocols (Nazarian, and Filiberti., 1993; Chen et al., 1994; Mohammad et al., 1994), ii.) development of resilient modulus maps (Baladi et al., 2009), iii.) effect of soil suction on resilient modulus (Sawangsuriya, et al., 2009; Khoury et al., 2011), iv.) comparisons between laboratory resilient modulus and resilient modulus backcalculated from non-destructive testing, (NDT) (Baladi et al., $2009), v$.) the development of models to evaluate the variation of resilient modulus with respect to water content changes (Khoury, et al., 2009; Hossain, 2009; Soliman and Shalaby, 2011; Taamneh and Liang, 2011; Muhanna et al., 1998; Mohammad, et al., 1999; Santha, 1994), and vi.) the evaluation of the model embedded in the new mechanistic-empirical design guide (Bulut et al., 2013).

Considerable research has been undertaken in the field; however, new roads and highways do not appear to last for the full design time period. There are many variables involved in the performance of a pavement structure once it is put into service. Rain and temperature are factors that are known to cause damage to pavements. Pavement design methods proposed prior to the release of the new AASHTO design guide for new and rehabilitated pavements, design the structure based on a single resilient modulus value for the subgrade. On the other hand, the mechanisticempirical design guide utilizes a model which simulates changes in resilient modulus during the service life of the structure. The data is then used to determine performance in terms of rutting.

Models for the prediction of resilient modulus changes due to variations on water content have been developed in foreign countries; however, each country needs to develop its own predictive models that can be introduced into its own design guides. The results presented in this paper are some of the initial efforts of the Mexican Transportation Institute (Research Center) to develop a model for the soils commonly found in Mexico. It is worth mentioning that the model shown in this paper takes into account just two paths of water change (lineal fashion): wetting or drying; however, the authors are aware that in real field conditions the materials can undergo cycles of wetting-drying-wetting, etc; this will be studied in another research project.

\section{CONSTITUTIVE MODELS FOR RESILIENT MODULUS}

To evaluate the nonlinear stress-strain characteristics of subgrade soils, Seed et al., (1955) first proposed the use of resilient modulus. Resilient modulus was defined as a relationship between deviator stress and recoverable deformation. Since then, many constitute models have been proposed for modeling resilient modulus. Examples of these models are as follows:

Moossazadeh and Witczak (1981) proposed the resilient modulus model that has deviator stress as the only attribute of the model.

$$
\mathrm{M}_{\mathrm{r}}=k_{1}\left(\sigma_{d}\right)^{k_{2}}
$$

where $\sigma_{d}$ is the deviator stress and $k_{1}$ and $k_{2}$ are constants dependent on material type and soil physical properties.

Uzan (1985) developed a model to overcome the bulk stress model limitations by including the deviatoric stress to account for the actual field stress state. The model was written as:

$$
\mathrm{M}_{\mathrm{r}}=k_{1} \theta^{k_{2}} \sigma_{d}^{k_{3}}
$$

where $\mathrm{k}_{1}, \mathrm{k}_{2}$ and $\mathrm{k}_{3}$ are material constants and $\theta$ and $\sigma_{\mathrm{d}}$ are bulk and deviatoric stress, respectively.

Uzan's model was later normalized and expressed as:

$$
\mathrm{M}_{\mathrm{r}}=k_{1} P_{a}\left(\frac{\theta}{P_{a}}\right)^{k_{2}}\left(\frac{\sigma_{d}}{P_{a}}\right)^{k_{3}}
$$

Another model was utilized in the protocol NCHRP 1-28A (i.e., laboratory determination of resilient modulus for flexible pavement design). The equation was written as:

$\mathrm{M}_{\mathrm{r}}=k_{1} P_{a}\left(\frac{\theta-3 k_{6}}{P_{a}}\right)^{k_{2}}\left(\frac{\tau_{o c t}}{P_{a}}+k_{7}\right)^{k_{3}}$

where, $\mathrm{Mr}$ : resilient modulus; $\theta$ : bulk stress; $k_{i}$ : regression constants, $P_{a}:$ atmospheric pressure and $\tau_{\text {oct }}$ octahedral shear stress which is expressed as:

$\tau_{\text {oct }}=\frac{1}{3} \sqrt{\left(\sigma_{1}-\sigma_{2}\right)^{2}+\left(\sigma_{2}-\sigma_{3}\right)^{2}+\left(\sigma_{3}-\sigma_{1}\right)^{2}}$

$\sigma_{1}, \sigma_{2}$ and $\sigma_{3}$ : principal stresses.

The model implemented in the mechanistic-empirical AASHTO Guide for the Design of New and Rehabilitated Pavement Structures is used for fine and granular soils. This model is defined as:

$\mathrm{M}_{\mathrm{r}}=k_{1} P_{a}\left(\frac{\theta}{P_{a}}\right)^{k_{2}}\left(\frac{\tau_{o c t}}{P_{a}}+1\right)^{k_{3}}$

Rahim and George (2005) developed a model to predict resilient modulus based on different stress states and basic properties. 
The authors considered different stress ratios which were plotted versus resilient modulus. Two stress ratios utilized were $\left(\sigma_{d} / \sigma_{c}\right)$ and $\left(\theta / \sigma_{d}\right)$ for fine and coarse-grained soils, respectively. Rahim and George stated that the slope of the curves depended on the physical properties of each soil and proposed two models to predict resilient modulus. The models for fine and coarse-grained soils, respectively, were written as:

$\mathrm{M}_{\mathrm{r}}=k_{1} P_{a}\left(1+\frac{\sigma_{d}}{1+\sigma_{c}}\right)^{k_{2}}$

$\mathrm{M}_{\mathrm{r}}=k_{1} P_{a}\left(1+\frac{\theta}{1+\sigma_{d}}\right)^{k_{2}}$

where, $\mathrm{M}_{\mathrm{r}}$ : resilient modulus $(\mathrm{MPa}) ; \sigma_{\mathrm{d}}$ : deviator stress $(\mathrm{kPa}) ; \sigma_{\mathrm{c}}$ : confining pressure $(\mathrm{kPa}) ; \theta$ : bulk stress $(\mathrm{kPa}) ; \mathrm{P}_{\mathrm{a}}$ : atmospheric pressure $(\mathrm{kPa}) ; \mathrm{k}_{1}$ and $\mathrm{k}_{2}$ : model parameters.

After the models were established, the values of $k_{1}$, and $k_{2}$ were correlated with properties such as liquid limit, water content, dry unit weight, and percent passing the 200 sieve.

Rahim and George (2005) did not directly use the stress ratio $\left(\sigma_{d} / \sigma_{3}\right)$ as a variable in their equations (i.e., equations 6 and 7$)$. The authors of this paper decided that a power model could be used to fit the data because all points from a test show a unique relationship (equation 8).

$\mathrm{M}_{\mathrm{r}}=k_{1}\left(\frac{\sigma_{d}}{\sigma_{3}}\right)^{k_{2}}$

Brown (1996) also proposed a similar empirical model. The model related resilient modulus to effective stress and was expressed as:

$\mathrm{M}_{\mathrm{r}}=K\left(\frac{p_{o}^{\prime}}{q_{r}}\right)^{n}$ where $K$ and $n$ depend on the soil type, $p_{o}^{\prime}$ is the initial mean normal effective stress and $q_{r}$ is the repeated deviator stress.

The applicability of model 8 is evaluated for the prediction of resilient modulus changes associated with water content variations.

\section{MATERIALS AND SAMPLE PREPARATION}

\section{Materials}

A total of five types of fine-grained materials were utilized in this study. The soils were classified as $\mathrm{CH}, \mathrm{ML}$ and SM according to the USCS soil classification system. Soil property tests conducted in this study included optimum water content and maximum dry unit weight (ASTM D 698), Atterberg limits (ASTM D 4318), specific gravity (ASTM D 854) and percent finer than 200 sieve (ASTM D 1140). The index and compaction properties are summarized in Table 1.

\section{Sample Preparation and Conditioning}

Sample Compaction

In preparing the specimens, a specified amount of soil was thoroughly mixed with tap water to achieve optimum water content conditions (i.e., for the Proctor standard test). The material was then allowed to cure overnight in a sealed plastic bag. The mass of the soil required to achieve the maximum dry unit weight was weighed and compacted into the split mold (7.1 $\mathrm{cm}$ diameter and $14.4 \mathrm{~cm}$ height) in eight layers with a rammer (1 kg mass) dropped from a height of $30 \mathrm{~cm}$. To compact each layer, the number of drops was calculated so that the maximum dry unit weight was achieved. After the final lift was compacted, the sample was trimmed to form a plane surface across the top of the mold.

Sample Conditioning

The specimens were then extruded from the mold and the dimensions and mass were recorded. After compaction, some

Table 1. Index properties and compaction characteristics

\begin{tabular}{|c|c|c|c|c|c|c|c|c|}
\hline \multirow{2}{*}{$\begin{array}{c}\text { Soil } \\
\text { classification }\end{array}$} & \multicolumn{3}{|c|}{ Atterberg limits } & \multirow{2}{*}{ Gs } & \multirow{2}{*}{$\begin{array}{l}\% \text { passing } 200 \\
\text { sieve }\end{array}$} & \multirow{2}{*}{$\%$ sand } & \multicolumn{2}{|c|}{ Compaction characteristics (ASTM D698 } \\
\hline & LL (\%) & PL (\%) & $\mathrm{PI}(\%)$ & & & & $w_{\text {opt }}(\%)$ & $V_{d \max }\left(k N / m^{3}\right)$ \\
\hline $\mathrm{CH}$ (Tlacote) & 72 & 26 & 46 & 2.59 & 92.9 & 7.1 & 33.00 & 12.56 \\
\hline ML (Misha) & 44 & 33 & 11 & 2.56 & 87.0 & 13.0 & 30.50 & 13.33 \\
\hline SM (Los Cues) & NP & NP & NP & 2.52 & 37.0 & 63.0 & 23.54 & 14.04 \\
\hline $\mathrm{CH}(\mathrm{IMT})$ & 66 & 41 & 25 & 2.61 & 85.7 & 14.3 & 30.00 & 13.32 \\
\hline $\mathrm{CH}$ (Jalisco) & 54 & 30 & 24 & 2.72 & 95.5 & 4.50 & 29.30 & 14.11 \\
\hline
\end{tabular}




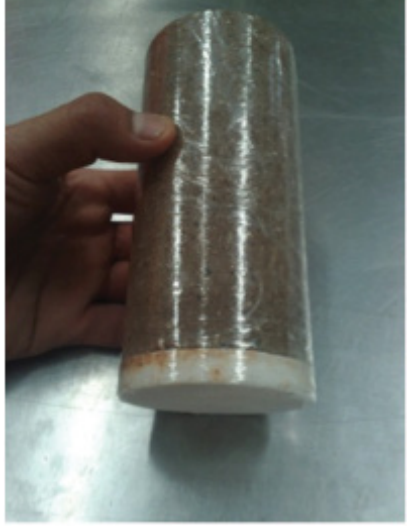

(a)

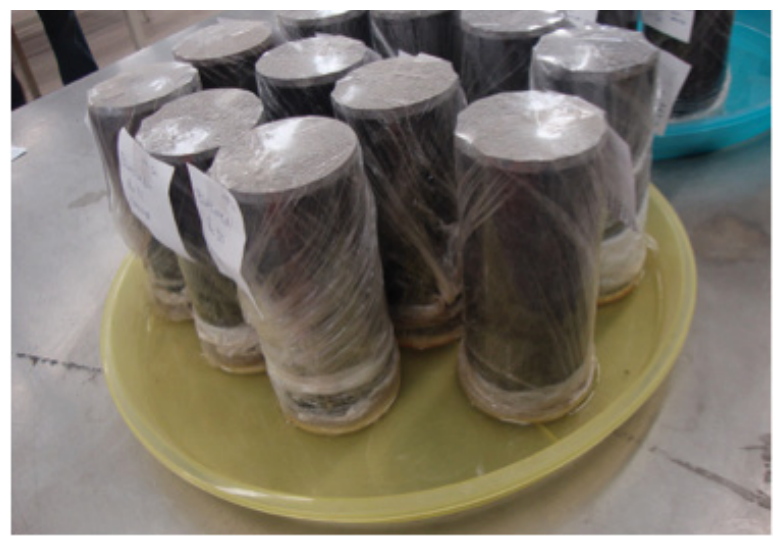

(b)

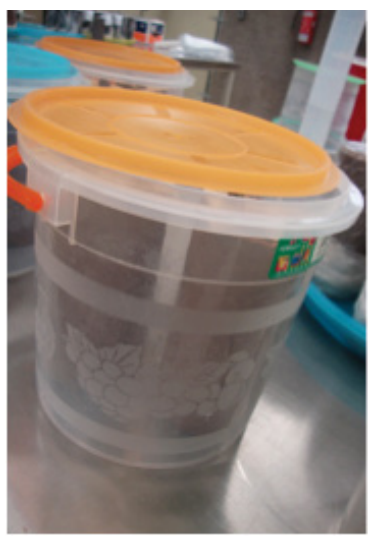

(c)

Figure 1. (a) Specimen placed on a porous stone; (b) Specimens placed on a tray with water to increase the water content through capillarity; (c) Specimens placed in a container to lose water through evaporation.

specimens were tested for the measurement of resilient modulus. Other specimens were wetted and others were dried (this to simulate post-compaction conditions). To simulate an increment in water content, the samples were allowed to imbibe water from a container after being placed over a porous stone and wrapped with a plastic sheet to avoid the loss of water content by evaporation (Figure 1a and $1 \mathrm{~b}$ ). To reduce the water content of the other specimens, they were placed in a container and allowed to slowly lose moisture (Figure 1c). The slow removal of moisture prevented the specimens from cracking. Once the specimens were allowed the designated time required to imbibe or lose water (e.g., 1, 5, 10, 20, 30, 60 days) they were wrapped in plastic (no weight was recorded at this point) and stored in bags for at least two weeks before running the test. This allowed time for the equalization of moisture throughout the entire specimen.

\section{RESILIENT MODULUS TESTING PROTOCOL}

Figure 2 shows the triaxial test equipment utilized in this research. The resilient modulus tests were conducted in accordance with the NCHRP 1-28A test protocol. According to this protocol, the resilient modulus test for subgrade soils consists of applying a cyclic-haversine shaped load for a duration of 0.2 seconds and a rest period of 0.8 seconds. During the test, 16 sequences with different states of stress were applied as summarized in Table 2.

Sequence zero was used for conditioning the soil specimens. In each of the other 15 sequences, 100 load cycles were applied; the vertical displacement and load for the last five cycles were recorded and used to determine the resilient modulus, $M_{r}$. The load was measured using an external load cell with a capacity of $10.1 \mathrm{kN}$ and the vertical displacements were measured using two LVDTs fixed opposite sides from the piston rod outside the chamber. The LVDTs have a maximum stroke length of $2.5 \mathrm{~mm}$.

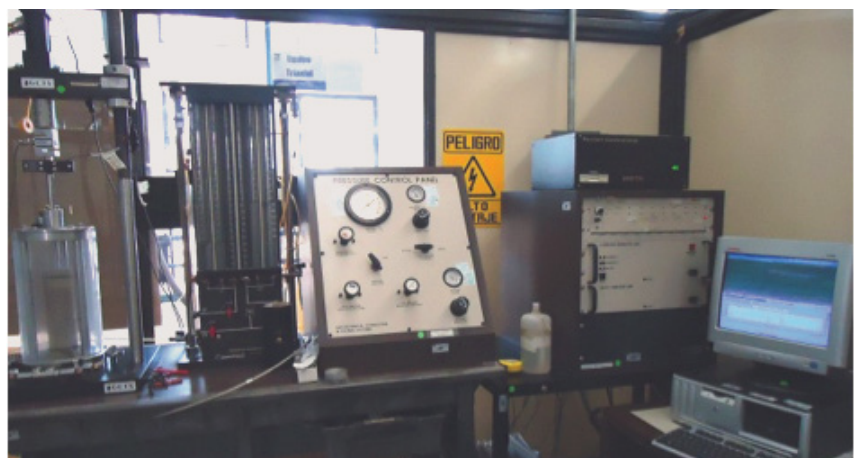

Figure 2. Resilient modulus testing equipment

Table 2. Stress states applied during the resilient modulus test

\begin{tabular}{|c|c|c|c|c|}
\hline $\begin{array}{c}\text { Sequence } \\
\text { No. }\end{array}$ & $\begin{array}{c}\text { Confining } \\
\text { pressure } \sigma_{3} \\
(\mathrm{kPa})\end{array}$ & $\begin{array}{c}\text { Contact } \\
\text { stress (kPa) }\end{array}$ & $\begin{array}{c}\text { Cyclic stress } \\
\text { (kPa) }\end{array}$ & $\begin{array}{c}\text { Number of } \\
\text { cycles }\end{array}$ \\
\hline 0 & 27.6 & 5.5 & 48.3 & 1000 \\
\hline 1 & 55.2 & 11.0 & 27.6 & 100 \\
\hline 2 & 41.4 & 8.3 & 27.6 & 100 \\
\hline 3 & 27.6 & 5.5 & 27.6 & 100 \\
\hline 4 & 13.8 & 2.8 & 27.6 & 100 \\
\hline 5 & 55.2 & 11.0 & 48.3 & 100 \\
\hline 6 & 41.4 & 8.3 & 48.3 & 100 \\
\hline 7 & 27.6 & 5.5 & 48.3 & 100 \\
\hline 8 & 13.8 & 2.8 & 48.3 & 100 \\
\hline 9 & 55.2 & 11.0 & 69.0 & 100 \\
\hline 10 & 41.4 & 8.3 & 69.0 & 100 \\
\hline 11 & 27.6 & 5.5 & 69.0 & 100 \\
\hline 12 & 13.8 & 2.8 & 69.0 & 100 \\
\hline 13 & 55.2 & 11.0 & 96.6 & 100 \\
\hline 14 & 41.4 & 8.3 & 96.6 & 100 \\
\hline 15 & 27.6 & 5.5 & 96.6 & 100 \\
\hline 16 & 13.8 & 2.8 & 96.6 & 100 \\
\hline
\end{tabular}




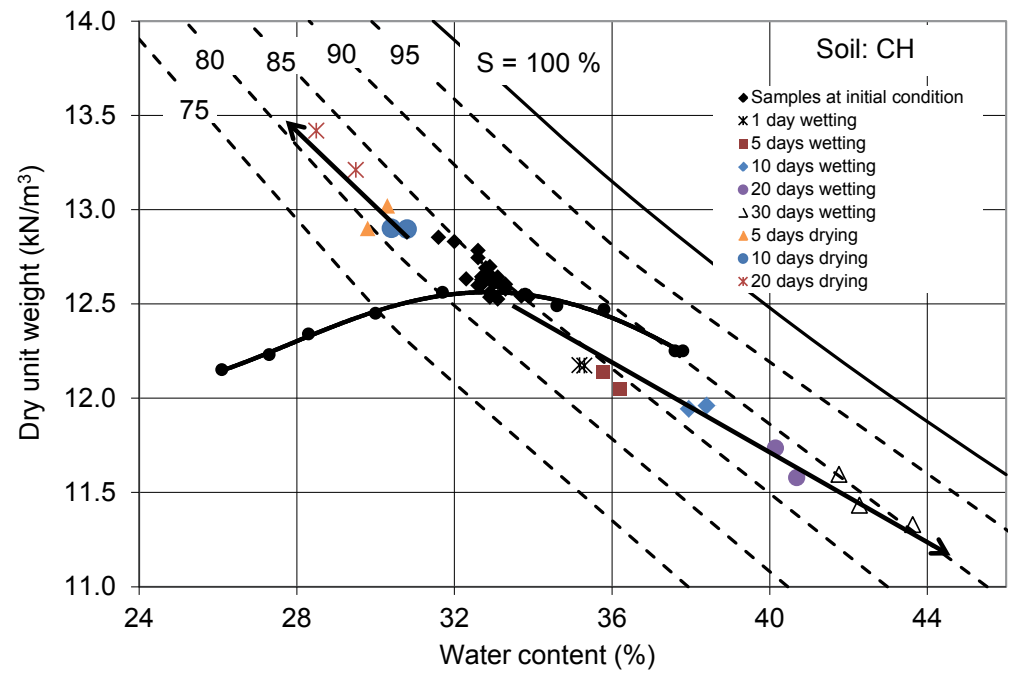

Figure 3. Changes in dry unit weight of samples due to the change in water content for the $\mathrm{CH}$ soil (CH Tlacote)

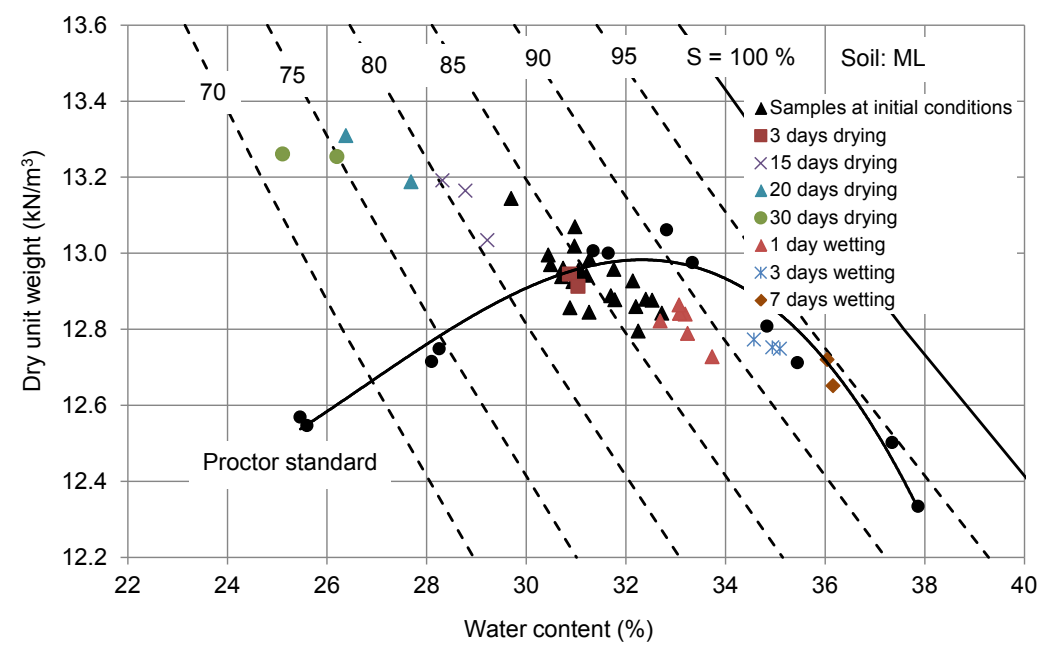

Figure 4. Changes in dry unit weight of samples due to the change in water content for the ML soil

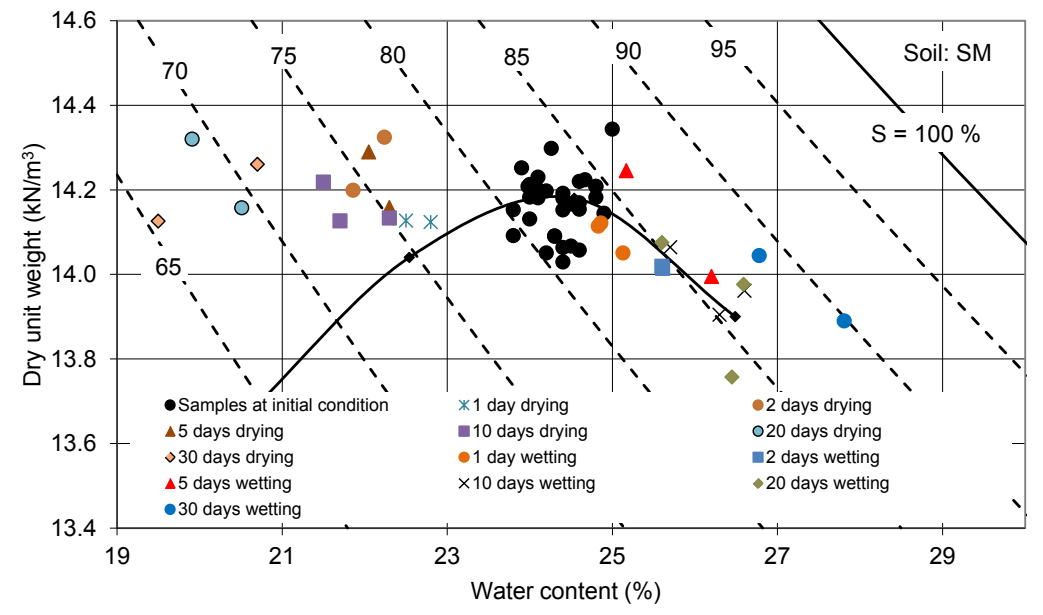

Figure 5. Changes in dry unit weight of samples due to the change in water for the SM soil content

\section{DISCUSSION OF RESULTS}

\section{Compacted Soil Specimens}

To ensure that the resilient modulus values obtained for each condition were repeatable, two or three replicates were tested for each condition. During compaction, care was taken to compact the specimens to the same unit weights and optimum water contents. An effort was made to have the same initial conditions for all specimens; however, there was a small difference in initial conditions. For example, for the $\mathrm{CH}$ soil, the actual water contents averaged about $0.2 \%$ below the target while the dry unit weights averaged $0.1 \mathrm{kN} / \mathrm{m}^{3}$ above the target value. For the ML soil, the averaged water content was $0.86 \%$ above the target value and $0.40\left(\mathrm{kN} / \mathrm{m}^{3}\right)$ below for the dry unit weight. In the case of the SM soil, both characteristics (i.e., water content and dry unit weight) were above the target value with amounts of $0.80 \%$ and $0.12 \mathrm{kN} / \mathrm{m}^{3}$, respectively.

\section{Variations of Dry Unit Weight and Water} Content Due to Gain or Loss of Water

The soil specimens were not confined during conditioning (by wetting or drying). Therefore, some volume change was observed for each of the specimens. Figures 3, 4, and 5 show the initial conditions of the specimens and the position prior to performing the resilient modulus tests. The specimens of the SM soil changed water content with almost no volume change. On the other hand, it is noted that the $\mathrm{CH}$ (Tlacote) specimens with 30 days of wetting, changed water content by approximately $11 \%$ while the SM and ML soils changed water content by no more than $4 \%$, making clear that the $\mathrm{ML}$ soil was wetted only for seven days. In terms of degree of saturation changes, the SM changed from 65 and 90\%, the $\mathrm{CH}$ (Tlacote) from 80 to $90 \%$, and the ML from 70-95\%. 


\section{Power Model for Resilient Modulus Testing}

Some authors have developed correlations in order to estimate the resilient modulus based on a particular stress state (Hossain and Kim, 2014; Lee et al., 1997; Jones and Witczak, 1997; Thompson and Robnett, 1979). However, each test series in the present study provided 16 values of resilient modulus, $M_{r}$. The author's research objective was to develop a model that would satisfy all the values involved. The model that most closely complied with these requirements was the one shown in equation (8).

After taking this model, all tests were then plotted as a graph of $\left(\sigma_{d} / \sigma_{3}\right)$ versus resilient modulus (Figures 6 and 7). Figures 6 and 7 shows the typical fitting curves and corresponding power models of two soils tested at different water contents.

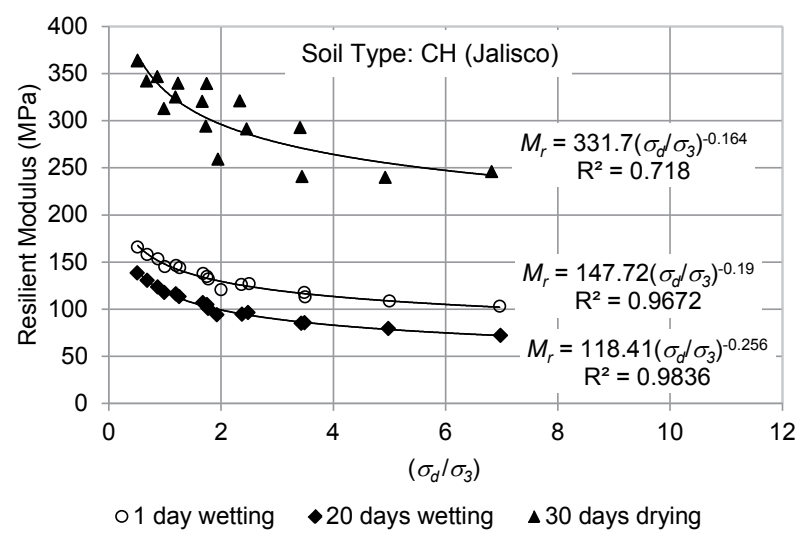

Figure 6. Results of resilient modulus for one of the $\mathrm{CH}$ soils fitted using a power model

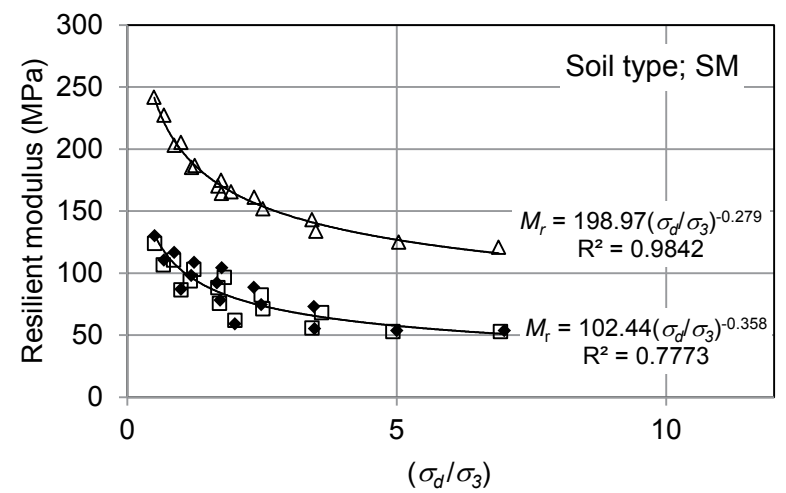

- Optimum water content $\square 30$ days of wetting $\Delta 30$ days of drying

Figure 7. Results of resilient modulus for the SM soil fitted using a power model
To evaluate the constants $k_{1}$ and $k_{2}$ based on experimental results, model (8) was transformed to:

$\log \mathrm{M}_{\mathrm{r}}=\log k_{1}+k_{2} \log \left(\frac{\sigma_{d}}{\sigma_{3}}\right)$

After summarizing the values of $k_{1}$ and $k_{2}$ and finding that they follow a normal distribution, they were correlated (utilizing the statistical software MINITAB) with water content variation $\left(\mathrm{w}-\mathrm{w}_{\mathrm{opt}}\right)$. The model for $\mathrm{k} 1$ and the analysis of the coefficients and adequacy of the model is shown in Table 3. This table indicates that both the constant and (w-wopt) explain the variation of $k 1$. On the other hand, the model is adequate as $p$ is smaller than 0.05 .

As observed from Figure 8, the correlation of $\mathrm{k}_{2}$ with variation in water content was not strong; $k_{2}$ was correlated with other physical properties, but no relationship was obtained. As a matter of fact, $k_{2}$ has a very small range of variation, between -0.383 and -0.073 , with a mean value of -0.26 . The model (12) was evaluated taking into account values of $-0.1,-0.2,-0.3$ and -0.4 . The value of -0.2 provided the best $R_{2}$.

Replacing the correlation of $\mathrm{k}_{1}$ and -0.2 for $\mathrm{k}_{2}$ in equation 8 , then, the model proposed by the authors of this paper is expressed as:

$M_{r}=e^{1.98-0.0714\left(w-w_{o p t}\right)} \times\left(\frac{\sigma_{d}}{\sigma_{3}}\right)^{-0.2}$

Table 3. Analysis of regression and variance for $\boldsymbol{k}_{1}$ constant

\begin{tabular}{|l|c|c|c|c|c|}
\hline \multicolumn{2}{|c|}{ Regression equation: } & \multicolumn{3}{c|}{ logk $k_{1}=1.98-0.0714\left(w-w_{\text {opt }}\right) \quad$ (11) } \\
\hline Predictor & Coef & SE Coef & T & $\mathrm{p}$ \\
\hline Constant & 1.97656 & 0.00421 & 469.15 & 0.000 \\
\hline$\left(w_{-} w_{\text {opt }}\right)$ & -0.071363 & 0.001132 & -63.04 & 0.000 \\
\hline S $=0.116640$ & R-Sq $=83.6 \%$ & R-Sq(adj $)=$ & $83.6 \%$ & \\
\hline Analysis of Variance \\
\hline Source & DF & SS & MS & F & $p$ \\
\hline Regression & 1 & 54.063 & 54.063 & 3973.74 & 0.000 \\
\hline Residual error & 778 & 10.585 & 0.014 & & \\
\hline Total & 779 & 64.647 & & \\
\hline
\end{tabular}




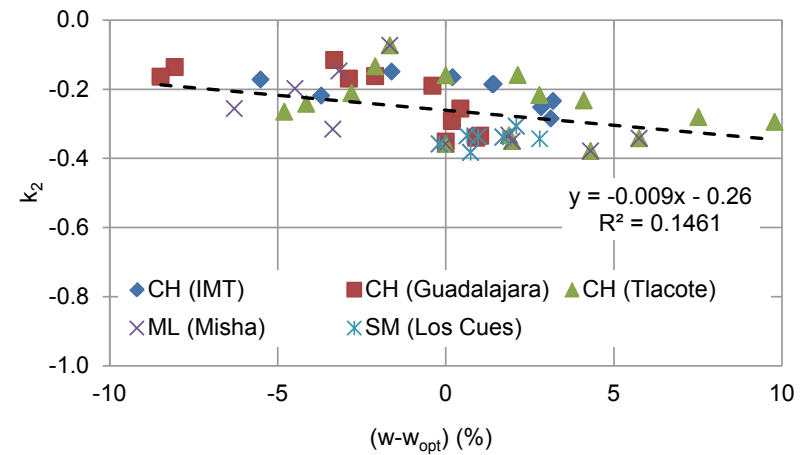

Figure 8. Linear relationship between variations of water content versus $\mathrm{k}_{2}$

where: $M_{r}$ is the resilient modulus $(\mathrm{MPa}) ;\left(w-w_{\text {opt }}\right)$ is the variation of water content regarding the optimum (\%); $\sigma_{d}=$ deviator stress $(\mathrm{kPa})$, and $\sigma_{3}=$ confining pressure $(\mathrm{kPa})$.

The predicted resilient modulus obtained when using equation (12) provided a close correlation to actual resilient modulus (Figure 9). It is worth mentioning that the model put forward in this document was obtained for samples that were wetted or dried in a linear way. There is a need to develop models to simulate several cycles of wetting and drying, and also to take into account the effect of hysteresis.

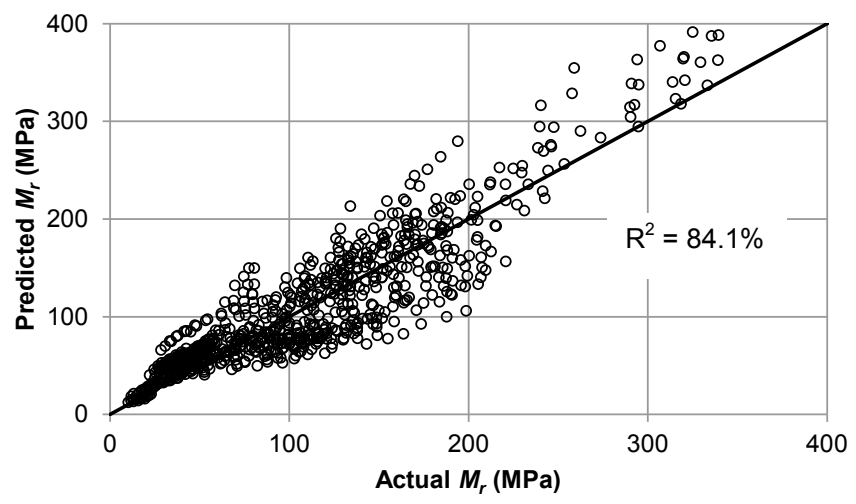

Figure 9. Actual resilient modulus versus predicted modulus
The analysis of variance of the model is shown in Table 4. As the $p$ value is smaller than 0.05 , then the model is adequate to describe the resilient modulus behavior.

Table 4. Analysis of variance of the model

\begin{tabular}{|l|c|c|c|c|c|}
\hline \multicolumn{5}{|l|}{ Analysis of Variance } \\
\hline Source & DF & SS & MS & F & p \\
\hline Regression & 1 & 3143228 & 3143228 & 4123.41 & 0.000 \\
\hline Residual error & 778 & 593061 & 762 & & \\
\hline Total & 779 & 3736289 & & & \\
\hline
\end{tabular}

\section{CONCLUSIONS}

The service life of a pavement structure depends to a large extent on the stiffness (i.e., resilient modulus) of the unbound materials; however, this property is known to vary seasonally. This study focused on quantifying the seasonal variation of $M_{r}$.

A resilient modulus model was evaluated for five soils, (i.e., $\mathrm{CH}, \mathrm{ML}$, and SM soil). It was found that variations in resilient modulus could be predicted in terms of knowing variables such as $\left(w-w_{\text {opt }}\right)$ and $\left(\sigma_{d} / \sigma_{3}\right)$. The model appears to provide close agreement with measured results (e.g., the $\mathrm{R}^{2}$ between predicted and measured results was 84.1). It is important to mention that the variation in dry unit weight was also studied as a variable to explain the change in resilient modulus. The dry unit weight variable was not included as a necessary variable because the $R^{2}$ only slightly increased. It was the authors' conclusion that it is better to use a model with the least possible number of variables.

The variation of degree of saturation (S-Sopt) was also correlated with $\mathrm{k} 1$ but the $\mathrm{R}^{2}$ was smaller than 0.6 , thus, it was decided not used it as a variable in the resilient modulus model. 


\section{REFERENCES}

1. Baladi, G.Y., Dawson, T.A., and Haider, S.W. (2009). Laboratory Subgrade Resilient Modulus Design Values for the State of Michigan. 88th Transportation Research Board Annual Meeting. Washington D.C.

2. Baladi, G.Y., Sessions, C.P., and Haider, S.W. (2009). Backaclculated and Laboratory Measured Resilient Modulus Values. 88th Transportation Research Board Annual Meeting. Washington D.C.

3. Bayomy, F., El-Badawy, S., Awed, A. (2012). Implementation of the MEPDG for Flexible Pavements in Idaho. Report No. FHWA-ID-12-193. National Institute dor Advanced Transportation Technology, University of Idaho. Prepared for Idaho Transportation Division of Highways, Resource Center. May 2012.

4. Brown, S.F. (1996). Soil Mechanics in Pavement Engineering. Géotechnique 46. No. 3. Pp. 383-426.

5. Bulut, R., Muraleetharan, K.K. M., Zaman, M., Yue, E., Soltani, H., and Hossain, Z. (2013). Evaluation of the enhanced integrated climatic model for modulusbased construction specification for Oklahoma Pavements. Oklahoma Transportation Center. Report No. OTCREOS11.1-10-F.

6. Chen, D.H., Zaman, M.M., and Luguros, G. (1994). Resilient Moduli of Aggregate Materials: Variability due to Testing Procedure and Aggregate Type. Transportation Research Record 1462. Pp. 57-64.

7. Hossain, M. S. and Kim, W.S. (2014). Estimation of Subgrade Resilient Modulus Using the Unconfined Compression Test. Final Report: VCTIR 15-R12. Virginia Center for Transportation Innovation and Research.

8. Hossain, M.S. (2009). Estimation of Subgrade Resilient Modulus for Virginia Soil. 88th Transportation Research Board Annual Meeting. Washington D.C.

9. Jones, M. P., and Witczak, M.W. (1997). Subgrade Modulus on the San Diego Test Road. Transportation Research Record 641, Transportation Research Board, National Research Council, Washington, D.C. (1977). Pp. 1-6.

10. Khoury, N., Brooks, R. Musharraf, Z.M., and Khoury, N.C. (2009). Variations of Resilient Modulus of Sub-grade Soils with Post-Compaction Moisture Contents. 88th Transportation Research Board Annual Meeting. Washington D.C.

11. Khoury, C., Khoury, N., and Miller, G. (2011). Effect of cyclic Suction History (Hydraulic Histeresis) on Resilient Modulus of Unsaturated Fine-Grained Soil. 90th Transportation Research Board Annual Meeting. Washington D.C.

12. Lee, W., Bohra, N.C., Altschaeffl, A.G., and White, T.D. (1997). Resilient Modulus of Cohesive Soils. Journal of Geotechnical and Geoenvironmental Engineering. Vol. 123. No. 2. February, 1997. Pp. 131-135.

13. Mohammad, L.N., Huang, B., Puppala, A., and Allen, A.J. (1999). Regression moldel for Resilient Modulus of Subgrade Soils. Transportation Research Record 1687. Pp. 47-54.

14. Mohammad, L.N., Puppala, A.J., and Alavilli, P. (1994). Influence of Testing Procedure and LVDT Location on Resilient Modulus of Soils. Transportation Research Record 1462. Pp. 91-101.

15. Moossazadeh, J., and Witczak, M.W. (1981). Prediction of Subgrade Moduli for Soil that Exhibits Nonlinear Behavior. Transportation Research Record 810. Transportation Research Board, National Research Council, Washington, D.C.

16. Muhanna, A.S., Rahman, M.S., and Lambe, P.C. (1998). A model for Resilient Modulus and Permanent Strain of Subgrade Soils. Transportation Research Record 1619. Pp. 82-93.

17. Nazarian, S., Feliberti, M. (1993). Methodology for Resilient Modulus on Cohesionless Subgrade Soils. Transportation Research Record 1406. Pp. 108-115.

18. NCHRP. Laboratory Determination of Resilient Modulus for Flexible Pavement Design. National Cooperative Highway Research Program (NCHRP). Transportation Research Board of National Academies. Washington, 2004.

19. Rahim, A.M. and George, K.P. (2005). Models to estimate subgrade resilient modulus for pavement design. The International Journal of Pavement Engineering. Vol. 6. No. 2. June 2005. Pp. 89-96.

20. Santha, B. L. (1994). Resilient modulus of subgrade soils: Comparison of two Constitutive Equations. Transportation Research Record 1462: Soils, Geology and Foundations. Transportation Research Board.

21. Sawansuriya, A., Edil, T.B., and Benson, C.H. (2009). Effect of Suction on the Resilient Modulus of Compacted Fine-Grained Subgrade Soils. 88th Transportation Research Board Annual Meeting. Washington D.C.

22. Seed, H. B., Chan, K., and Monismith, C. L. (1955). Effects of Repeated Loading on the Strength and Deformation of Compacted Clay. A paper prepared for presentation at the annual meeting of the Highway Research Board. January 11-14, 1955. Washington, D.C.

23. Soliman, H., and Shalaby, A. (2011). Developing Pavement Design Inputs for Fine-Grained Subgrade Soils in Manitoba. 90th Transportation Research Board Annual Meeting. Washington D.C.

24. Taamneh, M.M. and Liang, R.Y. (2011). Predicting Stress and Moisture Dependent Resilient Modulus of Cohesive Soils. 90th Transportation Research Board Annual Meeting. Washington D.C.

25. Thompson, M.R., and Robnett, Q.L. (1979). Resilient Properties of Subgrade Soils. Transportation Engineering Journal of ASCE. Vol. 105. No. TE1 (January 1979). Pp. 71-89.

26. Uzan, J. (1985). Characterization of Granular Material. Transportation Research Record No. 1022. Pp. 52-59. 